\title{
CHARITÉ
}

UNIVERSITÄTSMEDIZIN BERLIN

\section{A Case Study of Biological Nurturing}

\author{
Stefanie Inge Rosin
}

\section{Document type \\ Postprint (accepted version)}

This version is available at

https://doi.org/10.17169/refubium-26984

\section{Citation details}

Rosin SI. A Case Study of Biological Nurturing. Journal of Human Lactation. [Online] SAGE Publications; 2019;35(2): 318-322. DOI: 10.1177/0890334419829044

\section{Terms of use}

All rights reserved. This document is intended solely for personal, non-commercial use.

This is the peer reviewed version of the above mentioned article. This article may be used in accordance with the publisher policy for use of self-archived versions. 


\title{
A Case Study of Biological Nurturing
}

Case Report in the Journal of Human Lactation

https://doi.org/10.1177/0890334419829044 Corresponding Author: Stefanie Inge Rosin, PhD,

BNCLC, LLL leader, IBCLC in private practice in Berlin, Germany: https://www.stillberatungrosin.de/english/about-me/ Emails: info@stillberatung-rosin.de, Stefanie.Rosin@charite.de

\begin{abstract}
Introduction: This case of a mother and her two children, born 20 years apart, highlights how Biological Nurturing $(\mathrm{BN})$ supported a woman in meeting her personal breastfeeding goals. We know lack of breastfeeding support contributes to early weaning. Applying the principles of $\mathrm{BN}$ (unrestricted and laid-back breastfeeding) enabled this mother to return to breastfeeding without supplements.

Main Issue: After giving birth to her first son prematurely in 1997, the dyad was separated, and formula introduced. These interventions, combined with inadequate breastfeeding support, resulted in low milk supply and unplanned weaning by week six. In 2017, a full term sibling baby girl was born, with breastfeeding again beginning with concerns of low milk supply.

Management: Consultation with an International Board Certified Lactation Consultant successfully addressed common breastfeeding problems, including vasospasm and insufficient milk supply. Continuous emotional support helped this mother overcome perceived insufficient milk supply. Introducing BN led to breastfeeding without supplementation, by enabling the dyad to experience enjoyment, comfort and feeding autonomy.

Conclusion: While the repeated experience of insufficient milk supply two decades apart constituted a psychological barrier to exclusive breastfeeding, BN enabled reaching this mother's breastfeeding goals. BN appears to be a powerful tool for both breastfeeding initiation and overcoming breastfeeding difficulties, potentially setting new best practice standards.
\end{abstract}

\section{Keywords}

Biological Nurturing, breastfeeding initiation, breastfeeding support, infant feeding patterns, latch-on, mother-infant dyad

\section{Introduction}

This case study highlights Biological Nurturing (BN), defined as a neurobehavioral approach to breastfeeding initiation that aims to reduce latching problems and early unintended breastfeeding cessation (Colson, 2012). The conceptual framework of BN for lactation (Colson, Meek \& Hawdon, 2008), with its components and mechanisms, is displayed in Table 1. In BN, the angle at which mothers recline can be critical for breastfeeding success, also enabling unrestricted access to the breast and maternal comfort (Colson 2012). In her book on BN, Colson (2010a) demonstrated how a baby's innate reflexes and a mother's intuitive behavior promote joyful mother-child interaction, while latching occurs spontaneously.

This case follows a mother and her lactation experiences with two children, born 20 years apart (Figure 1). In both instances, insufficient milk supply and inadequate breastfeeding support caused problems with breastfeeding initiation. However, with the birth of her second child, BN and support from an International Board Certified Lactation Consultant (IBCLC) made the difference in her breastfeeding outcome. The participant discussed in this case gave written consent for publication, and read and approved the case as submitted. 


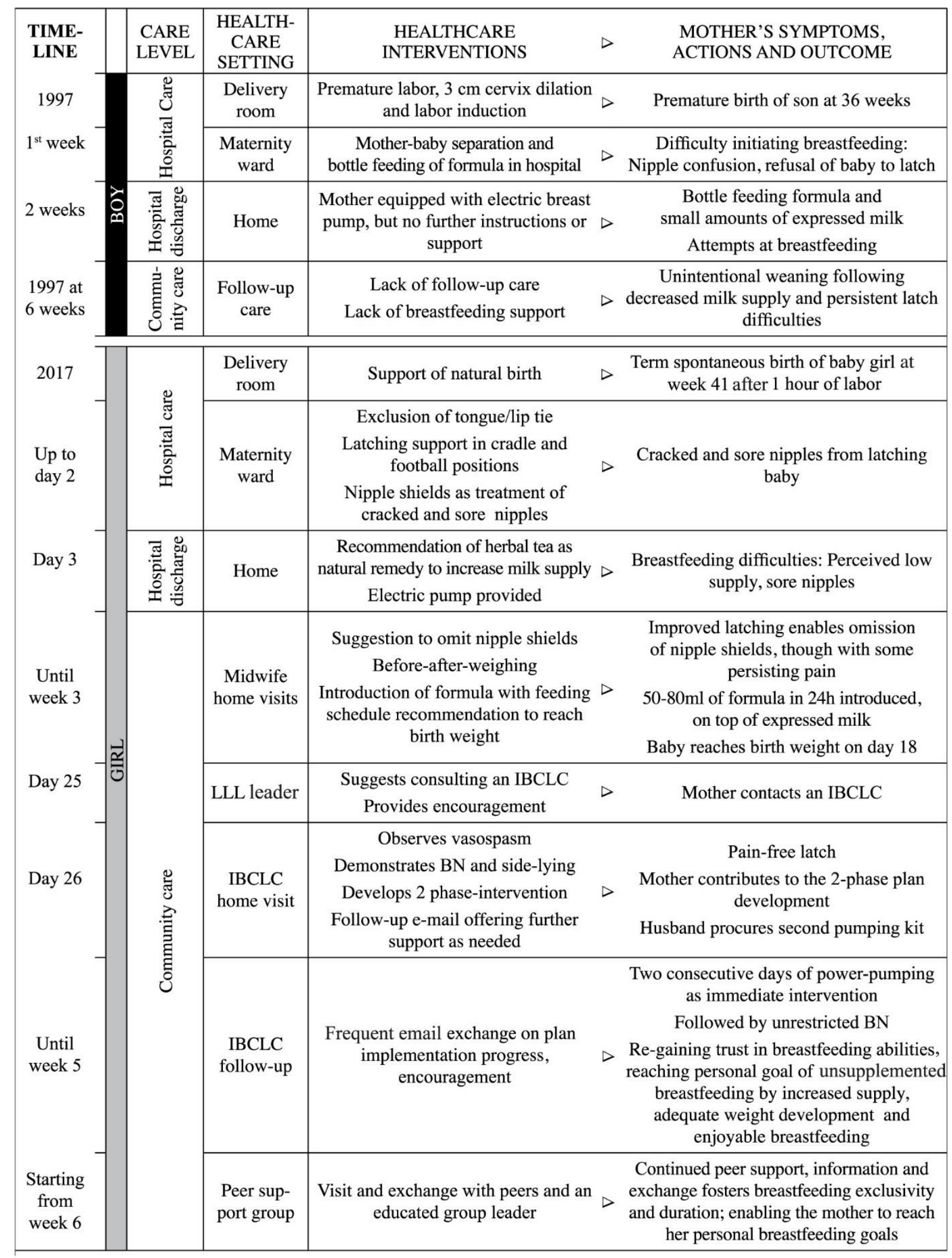

Figure 1. Timeline Case Study Biological Nurturing. 
Table 1. Key Components and Mechanisms of Biological Nurturing.

Components

- A range of maternal postures in semi-reclined position

- Full frontal body contact

- Primitive neonatal reflexes

- Instinctive maternal behavior

- Neonatal behavioral states

- Hormonal complexion
Mechanisms

- Versatility of lie

- Full frontal baby positions

- Works with gravity

- Maternal comfort

- Spontaneous mother-baby interaction leads to latching baby

- Mothers are focused on their babies

Reproduced from: Colson, Meek and Hawdon, 2008.

\section{History}

Lactation Experience in 1997

In 2017 this mother, a 38-year-old para two German Caucasian mother in a wealthy borough of Berlin, Germany, requested a breastfeeding consultation with the author. The mother's intention was to breastfeed for as long as desired, including six months of exclusive breastfeeding. Her history included her first child, a 2900g boy, born spontaneously in 1997 in a non-Baby-Friendly hospital, following induction at $3 \mathrm{~cm}$ cervical dilation and premature labor at week 36. The maternity ward featured a nursery for nighttime, but also for daytime whenever mothers needed rest. The infant was separated from his mother every night and was bottle-fed formula by hospital staff during these separations. By maternal report, staff had no time to support breastfeeding and her infant did not latch after these repeated separations, except for nonnutritive sucking.

Support for breastfeeding after hospital discharge was minimal.After hospital discharge the 19year-old mother lived with her own mother who had herself weaned early, convinced her own milk supply had been insufficient. The baby's father, aged 21, lived with his parents and was no support for the breastfeeding relationship. To address the mother's insufficient milk supply, the midwife supplied an electric pump, but offered no guidance for usage nor further breastfeeding support. The mother remained insecure about her ability to breastfeed. One night when baby cried uncontrollably, the grandmother purchased formula, believing insufficient milk supply "ran in the family". Increasing use of formula led to a further decrease in the mother's milk supply. At six weeks postpartum, the mother stopped breastfeeding and expressing, causing her frustration and grief. Reflecting on this experience, she commented:

"I am sad at not having been able to provide breastfeeding as a valuable asset to my son and myself. How can formula be introduced so easily to mother and child without a second thought and without good information about the risks, when so much is taken away from the motherbaby dyad? In comparison to my healthy daughter, my son suffered from many infectious diseases during infancy, and repeated otitis media."

\section{Lactation Experience in 2017}

Her second child, a girl, was born spontaneously in a Baby-Friendly hospital at 41 weeks after one hour of labor. The mother-baby dyad was healthy. The mother intended to breastfeed for six months exclusively, and to continue for a minimum of nine months. The mother developed bleeding nipples on day two; no tongue or lip tie was noted in her baby. She used the cradle and football positions, and the hospital staff provided nipple shields for pain relief. 
The midwife conducted several consecutive home visits and recommended discontinuing the nipple shield. As latching without the nipple shield improved with practice, the mother's nipples healed. Unaware of breastfeeding during baby's sleep states, she was shown how to wake up the baby for feeds, if necessary with a wet cloth. As the infant did not regain birth weight until day 18 , the physician and midwife, who conducted pre- and post-test weights, measuring $50 \mathrm{ml}$, deemed her milk supply insufficient. Thereafter, the mother began feeding $50-80 \mathrm{ml}$ of formula per 24 hours to her child, via bottle and teat. She reported nipple confusion when changing from breast to bottle and vice versa. She used a single-sided, electric hospitalgrade pump to express milk as often as possible after breastfeeding, and then bottle-fed the expressed milk.

The mother called a La Leche League (LLL) leader, via the German LLL website (https://www.lalecheliga.de), who advised her to contact an IBCLC, which she did on day 23 postpartum, reporting persisting nipple pain, mainly after feeds. She wrote in the IBCLC's contact form:

"Insufficient milk supply, baby keeps falling asleep at the breast, spits up a lot, supplementation $50 \mathrm{ml}$ maximum by bottle because of insufficient weight gain, shows few breastfeeding cues while oversleeping and missing feeds; then every other day wants to feed every hour."

\section{Observational Assessment and Management}

During a home visit on day 24 postpartum, the IBCLC observed nipple blanching and pain after feeds, consistent with vasospasm. The IBCLC guided the mother-baby dyad to BN, explaining its components and mechanisms (see Table 1 in supplementary files). The sidelying position was demonstrated for ease of breastfeeding at night. While the BN unrestricted breastfeeding might have sufficed to increase milk supply, the mother preferred using the pump as the first intervention, for a measurable and visible output of milk, in combination with breastfeeding. Taking the mother's preferences into consideration, the IBCLC suggested a two-stage procedure (Table 2):

Table 2. Two-stage Strategy of IBCLC Management Plan.

\begin{tabular}{lll} 
& Management Plan & Additional Maternal Actions \\
\hline Stage I & - Increase milk supply by following the power- & • Cover nipples to protect \\
& pumping schedule (The Milk Meg, 2015; & them against draft, apply warm \\
Morton et al., 2009) for two consecutive days & compresses \\
& Replace the supplementary formula & $\bullet$ Contact the IBCLC for \\
& continuously, including: Pumping both sides at & follow-up whenever needed \\
a time, latching infant as often as possible; & \\
getting enough rest & - Support throughout the program by the \\
father, a relative or other person of the & \\
mother's choice & \\
\hline Stage II & $\begin{array}{l}\text { Follow-up by unrestricted breastfeeding, } \\
\text { allowing the infant to establish the system of } \\
\text { demand and supply }\end{array}$ & $\begin{array}{l}\text { group for follow-up when } \\
\text { feeling up to it }\end{array}$
\end{tabular}




\section{Implementation of Stage 1}

To increase milk supply by power-pumping (see Figure 1 in supplementary files; The Milk Meg, 2015; Morton et al. 2009), the father procured a second pumping kit including tubing and breast shields, to express both sides simultaneously (Hemmelmayr, 2016). The mother followed the schedule of power-pumping 3-4 times per day for two consecutive days, with her husband's support. She also latched the infant unrestrictedly for a minimum of 10 times/24 hours, using BN predominantly, which she found easy to handle. Concurrently, she continued supplementing formula, with a one-time maximum of $150 \mathrm{ml}$ in 24 hours on day 25.

\section{Implementation of Stage 2}

After two days of power-pumping, she focused on direct breastfeeding, with occasional pumping between feeds. She eliminated formula completely on day 35 postpartum.

\section{Outcome}

After continued email follow-up with her IBCLC, she eliminated top-ups of her expressed milk, realizing she was supplementing more than the baby would take, out of fear that the infant might not be getting enough - in keeping with her family history of perceived insufficient milk supply (Gatti, 2008). Her inner conflict was revealed in one of her followup e-mails on day 52 postpartum:

\section{"Baby is well and thriving. I still express milk 1-2 times per day and feed the expressed milk, even though she often does not want the extra milk! She seems to be content with breastfeeding alone now."}

She reflected in hindsight that her belief of being unable to produce enough milk, unrefuted for two decades and repeated with her second child, represented a psychological barrier to exclusive breastfeeding. Expressing milk did not completely reassure her. Showing adequate weight gain was also helpful to overcome that barrier and end supplementation of expressed milk (see Figure 2 supplementary files; Guóth-Gumberger, 2017). Furthermore, the mother's relaxed state of mind experienced during unrestricted $\mathrm{BN}$ also contributed to overcoming her fears, and establishing a belief in her ability to produce an adequate milk supply.One remark said both during the first home visit and repeated in the IBCLC's follow-up email (day 24 postpartum) proved to be an especially helpful affirmation for the mother: "My child is competent where her food intake is concerned."

During BN, the mother repeatedly observed the infant feeding efficiently in sleep states. She expressed deep relief at having eliminated the bottle, enabling the baby to avoid the observed nipple confusion, and to breastfeed without pain, or any technical equipment. When asked whether BN had been helpful for her, she replied: "BN marked a breakthrough in breastfeeding my daughter. Sitting in this position alone was phenomenal." Referring to the unrestricted breastfeeding in BN position the mother remarked, "We nestled up together and enjoyed our cozy time snuggling together."

This mother, supported by her husband, complied with the two-stage plan, which resolved the pain and supply issues. After BN was introduced, no further healthcare intervention was necessary for meeting the mother's breastfeeding goals, except for continuous encouragement in an on-going e-mail exchange, as emotional support to overcome the perceived insufficient milk supply. Subsequently, the mother found continued encouragement in peer support groups, which further contributed to bolstering her confidence (Rosin \& Zakarija-Grković, 2016). She 
was enabled to reach her personal breastfeeding goals of breastfeeding without further supplementation in the first six months, continuing for nine months.

\section{Discussion}

Maternal comfort and the laid-back position are key mechanisms of the $\mathrm{BN}$ concept (Colson, 2010a). Applying these enabled this mother to allow her baby unrestricted breastfeeding. The laid-back position provides comfort and triggers baby's innate reflexes right from the start, enabling baby to latch autonomously and actively, promoting successful initiation, and enabling the development of motor skills as early as can be (Schaefer \& Genna, 2015; Colson, 2010b; Colson, 2005;). BN is also beneficial for developing cognitive skills (Williams \& Holley, 2013).

Maternal enjoyment is another key factor in the BN concept. The excerpts from the mother's conversations and correspondence illustrate how much she enjoyed feeding in the BN position. As Colson explains in her book (2010a), holding baby in natural habitat favors high oxytocin pulsatility of the mother baby dyad through close and constant body contact. Making use of both sleep and awake states for feeding favors adequate milk supply and saves energy for baby (Colson, 2002). Neonates may spend quite some time at the breast while "learning to breastfeed by breastfeeding" (Newman, 2018), representing an early postpartum feeding pattern. As is true for bonding, unrestricted breastfeeding can still be implemented at a later period if missed out in the early postpartum, just as this case demonstrates.

Recently considered as a skill mothers must learn (Rosin, 2010, p. 51), the gold standard for breastfeeding support has involved teaching mothers prescribed correct motions (Colson, 2012). BN allows both mothers and infants to follow their own instincts for latching (Colson, 2010a). According to Brazelton and Nugent (2011), three sleep and three awake states can be observed in neonates; quick and constant changes between them constitute normal infant behavior. However, new mothers are traditionally being taught only to feed baby in awake states, while feeding during sleep states has been considered inefficient, non-nutritive suckling (see Table 2 in supplementary materials). This constraint on mothers appears inappropriate, given the rapidly changing neonatal states.

The mother's observations in this study refute the common notion that a sleeping baby will not feed and a hungry baby will not sleep (Colson 2010a). In the BN concept, holding baby in natural habitat and feeding throughout sleep and awake states of the infant is crucial to successful breastfeeding initiation. During her BN research, Colson observed that efficient suckling and swallowing occurs both during sleep and awake states of baby (2010a), suggesting that a considerable part of milk intake may occur while baby is asleep, which this mother's observations confirm.

Although power-pumping and unrestricted breastfeeding successfully boosted the mother's milk supply, she continued to doubt her ability to produce enough milk. The personal care during the home visit, together with continuous emotional support from her IBCLC and peer support groups, were crucial factors in this mother overcoming the psychological barrier of perceived low milk supply. The BN concept provided comfort, enjoyment, relaxation, and feeding autonomy, enabling the mother-baby dyad to fully "take over," rendering further healthcare interventions unnecessary. 


\section{Conclusion}

This case study demonstrates that $\mathrm{BN}$, as a comprehensive approach to promoting instinctive mother-infant behavior and maternal comfort and enjoyment, had powerful tools to facilitate breastfeeding initiation without supplements and overcome breastfeeding difficulties. Breastfeeding support practitioners should provide strong emotional support concomitantly. As a new best practice goal to promote early feeding autonomy of the mother-baby dyad, BN may mark a paradigm shift in breastfeeding support. More research is needed to confirm the findings of this case study.

\section{Acknowledgments}

Thank you to the family that participated in this research.

Thanks to Suzanne Colson for her BN workshop and follow-up exchange on BN.

Thanks to Juanita Jauer Steichen for her thorough language revisions.

Thanks to James Akre for his feedback on wording.

Thanks to Christoph Rossmeissl and Pascal Steichen for design and revisions of figures.

\section{Declaration of Conflicting Interests}

The author declared no potential conflicts of interest with respect to the research, authorship, and/or publication of this article.

\section{Funding}

The author received no financial support for the research, authorship, and/or publication of this article.

\section{References}

Brazelton, T.B., \& Nugent, J.K. (2011). The neonatal behavioral assessment scale. Cambridge, UK: Mac Keith Press.

Colson, S.D. (2002). Womb to world: A metabolic perspective. Midwifery Today, 61, 9-11.

Colson, S.D. (2005). Maternal breastfeeding positions: Have we got it right? The Practising Midwife; 8(10), 24.

Colson, S.D. (2007). A non-prescriptive recipe for breastfeeding. The Practising Midwife, 10(9), 42-48.

Colson, S. (2008). Bringing nature to the fore. The Practising Midwife, 8(11), 14-19. Publishing.

Colson, S.D. (2010a). An introduction to biological nurturing. Amarillo, Texas: Hale

Colson S.D. (2010b). What happens to breastfeeding when mothers lie back?

Clinical applications of biological nurturing. Clinical Lactation, 1, 9-12.

Colson S.D. (2012). Biological nurturing: The laid-back breastfeeding revolution. Midwifery Today, 101, 9-11.

Colson, S.D., Meek, J.H., \& Hawdon, J.M. (2008). Optimal positions for the release of primitive neonatal reflexes stimulating breastfeeding. Early Human Development, 84, 441-449. doi: https://doi.org/10.1016/j.earlhumdev.2007.12.003

Gatti, L. (2008). Maternal perceptions of insufficient milk supply in breastfeeding. Journal of Nursing Scholarship, 40(4): 355-363. doi: 10.1111/j.1547-5069.2008.00234.x.

Guóth-Gumberger, M. (2017). LACTDOC: Program for Documentation and Weight Monitoring of Breastfed Babies. Retrieved from: http://breastfeeding-support.de/eng/pub.htm

Hemmelmayr, A. (2016). Power pumping. Lactation and breastfeeding ELACTA magazine, 4, 7-8. 
Horta, B., Kramer, M., \& Platt, R. (2001). Maternal smoking and the risk of early weaning: A meta-analysis. American Journal of Public Health, 91:304-307.

Margotti, E., \& Mattiello, R. (2016). Risk factors for early weaning. Revista da Rede de Enfermagem do Nordeste, 17(4), 537-544.

The Milk Meg. (2015). Power Pump your way to more milk. Retrieved from: https://themilkmeg.com/power-pump-your-way-to-more-milk/

Moreno, P., Schmidt, K. (2014). Breast-feeding and factors related to early weaning. Cogitare Enfermagem, 19(3):531-7.

Morton, J., Hall, J.Y., Wong, R.J., Thairu, L., Benitz, W.E, \& Rhine, W.D. (2009). Combining hand techniques with electric pumping increases milk production in mothers of preterm infants. Journal of Perinatology, 29, 757-764.

Newman, J. (2018). Breastfeeding. Empowering parents. E-book independently published by Jack Newman, Page 165, ISBN-10: 1717802842; ISBN-13: 978-1717802842

Rosin, S. (2010). Assessing the international situation of breastfeeding, lactation consulting and breastfeeding promotion as viewed by international, interdisciplinary experts and resulting recommendations. Bielefeld, Germany, University library, page 51. https://pub.uni-bielefeld.de/publication/2663500.

Rosin, S.I., \& Zakarija-Grković, I. (2016). Towards integrated care in breastfeeding support: a cross-sectional survey of practitioners' perspectives. International Breastfeeding Journal, 11,15. doi: https://doi.org/10.1186/s13006-016-0072-y

Schaefer, R., \& Genna, C. W. (2015). Physiologic breastfeeding: A contemporary approach to breastfeeding initiation. Journal of Midwifery \& Women 's Health, 60(5), 546553. doi: $10.1111 /$ jmwh.12319

Stuebe, A., Horton, B., Chetwynd, E., Watkins S., Grewen, K., \& Meltzer-Brody, S.(2014). Prevalence and risk factors for early, undesired weaning attributed to lactation dysfunction. Journal of Women's Health, 23(5): 404-412. http://doi.org/10.1089/jwh.2013.4506.

Williams, J., \& Holley, P. (2013). Linking motor development in infancy and early childhood to later school learning; Australian Journal of Child and Family Health Nursing, 10(1), 15-21.

Wood, N.K., Sanders, E. A. (2017). Mothers with perceived insufficient milk: Preliminary evidence of home interventions to boost mother-infant interactions. Western Journal of Nursing Research. 40, 8. https://doi.org/10.1177/0193945916687552 